\title{
Quantifying Gene Expression
}

\author{
Charles M. Roth* \\ Department of Chemical and Biochemical Engineering \\ and Department of Biomedical Engineering, Rutgers \\ University, 98 Brett Road, Piscataway, NJ 08854 USA
}

\begin{abstract}
Identifying those genes that are expressed and at what levels is an essential part of almost any biological inquiry at the cellular level. Techniques such as Northern blot have been in existence for decades to perform this task, but advances in molecular biology and bioinstrumentation have led to the development of a variety of new techniques with a range of sensitivities, throughputs and quantitative capabilities. This review focuses on the latter issue. For several commonly used gene expression techniques, the extent and range of quantitative applicability are reviewed, and approaches for maximizing the accuracy and precision of these measurements are discussed.
\end{abstract}

\section{Introduction}

With the genomes of a number of organisms fully sequenced and a rough draft of the human genome recently completed, the need for understanding gene expression is at an all-time high. Among the tens of thousands of human genes, only a small fraction are expressed in a given cell type at a particular time. Gene expression levels are dynamic, and patterns of gene expression change are integral to understanding biological processes ranging from development to inflammation to aging (Cao et al., 2001; Hoffmann et al., 2001; Livesey et al., 2000; Weindruch et al., 2001). Moreover, gene expression patterns are beginning to be viewed as useful diagnostics in areas such as classifications of tumors (Golub et al., 1999; Khan et al., 2001). Given recent successes in this area, it is likely that gene expression will increasingly constitute the basis for diagnostic assays that identify the onset of a disease and monitor its progression or remediation. Furthermore, it is envisioned that gene expression data, in conjunction with corresponding information on proteins and metabolites, will lead to the creation of realistic in silico models of cell behavior, which could be used in a wide variety of applications, such as design of antibiotics, drug target identification, and proliferation of stem cells for therapeutic implantation.

In all of these existing and emerging applications, the quality of the gene expression data is critical to its interpretation. However, different criteria of quality may be important, depending upon the application. For this reason,

*For correspondence. Email cmroth@rci.rutgers.edu; Tel. 732-445-4109 Fax. 732-445-2581. the newest techniques, such as DNA microarrays and quantitative PCR, are not in every instance preferable to more established techniques such as the Northern blot. Moreover, each technique can be made more or less quantitative through the appropriate use of controls and/ or standards. It is the aim of this review to discuss the inherent quantitative capabilities of several techniques for measuring gene expression levels, and to provide guidelines to make their application more quantitative. There are more techniques and variations than can be comprehensively discussed in a reasonable amount of space; the focus here is placed on techniques that are well developed to directly measure mRNA levels, rather than those that are designed to select differentially expressed genes from different sample populations.

\section{General Principles}

The essential components to detecting and quantifying the amount of a specific mRNA in a biological sample are a sufficient quantity of total or messenger RNA, sequencespecific probes, a sensitive detection method, and the proper controls and/or standards for interpreting the results.

For Northern blots, ribonuclease protection assays, and DNA microarray analysis, a sequence-specific probe is used to hybridize with the mRNA of interest (or a cDNA copy thereof). The probe sequences may either be long stretches of cDNA, in vitro transcribed RNA (riboprobes), or relatively short oligonucleotides of DNA, RNA or synthetic (e.g. peptide nucleic acid, PNA) chemistry. In any case, the affinity and specificity of the probe depend on its sequence, the temperature and the solution chemistry (especially, salt type and concentration). Frequently, probes in these applications are long (hundreds of bases), in which case selection of the sequence is not critical, so long as it is complementary to the target. For assays utilizing oligonucleotide probes, however, several variables must be considered, including probe length, GC content, hybridization temperature, and hybridization buffer (particularly magnesium concentration).

Because individual mRNA species are expressed in extremely small quantities, detection can be difficult. Partly for this reason, PCR-based approaches are becoming increasingly widespread for identifying and quantifying individual mRNAs. Usually, these employ reverse transcription (RT) as a first step, after which a gene-specific pair of oligonucleotide primers amplifies a region (hundreds of base pairs) of the resulting cDNA. The great advantage of PCR is the exponential growth of product, during cycles in which reagents are in excess and cross-reactions are minimal. Primer design is critical, though, in ensuring specific amplification of the gene of interest without nonspecific product formation (primer-dimers and/or amplification of cDNAs from other genes). One method of improving specificity is to perform a BLAST search of the target regions for primers to eliminate sequences expected to cross-hybridize (Jayaraman et al., 2000; Kang et al., 
1997). Since many organisms, such as mouse or rat, have not been fully sequenced, this is not exhaustive, so product specificity should be verified, e.g., by gel electrophoresis.

Most measurements of gene expression provide relative quantities of each mRNA, i.e., the ratio of an mRNA species between treated and control samples, although occasionally knowledge of the absolute amount is desired. The detection methods used for gene expression assays are almost universally based on fluorescence or radioactivity, neither of which can be directly related to quantities without the use of standards; thus, standards are needed for absolute quantification. In vitro transcribed RNAs added into the isolated RNA pool are useful because they can be carried through any processing (e.g., reverse transcription steps) with the sample; on the other hand, they must be handled and stored carefully to avoid ribonuclease contamination.

In both relative and absolute quantification, equal loading of samples to be compared is a critical issue, because of variability in the efficiency of RNA extraction and the processing of low volume quantities of sample. The total amount of RNA can be quantified by optical density reading at $260 \mathrm{~nm}$ and the purity assessed by the $A_{260} / A_{280}$ ratio and by gel electrophoresis. In addition, pipetting variance is an issue in the actual gene expression assay. Consequently, mRNA levels of a gene of interest are often normalized with respect to a housekeeping gene, one whose expression is not expected to vary in the samples under study. However, it is now known that two of the most commonly used housekeeping genes - $\beta$-actin and glyceraldehyde-3-phosphate dehydrogenase (GAPDH) - vary considerably in expression over a wide variety of conditions including development and tumorigenesis (Goidin et al., 2001; Warrington et al., 2000). Ribosomal RNAs, such as 18S rRNA, have been found to be present as a consistent fraction of total RNA and thus serve as better housekeeping standards (Schmittgen and Zakrajsek, 2000), although the necessity of using total RNA rather than poly(A) RNA may be a disadvantage in some protocols.

\section{Electrophoretic Techniques}

The conventional approach to mRNA identification and quantitation is through a combination of gel electrophoresis, which provides information on size, and sequence-specific probing. The Northern blot is the most commonly applied technique in this class and is still the benchmark against which other techniques are measured. The great advantage of the Northern blot is that the size of the transcript is obtained by gel electrophoresis, providing a crude verification of the accuracy of the probe; furthermore, it also allows for the identification of splicing variants that may be present in the RNA sample. Furthermore, a number of samples are electrophoresed and probed simultaneously, minimizing the variance in those steps. On the other hand, Northern blots are labor intensive, their sensitivity is limited by the capacity of the gel, and the number of steps involved creates more opportunity for the accumulation of experimental errors.

The ribonuclease protection assay (RPA) was developed as a more sensitive, less labor-intensive alternative to the Northern blot. Hybridization is performed with a labeled ribonucleotide probe in solution, after which non-hybridized sample and probe are digested with a mixture of ribonucleases (e.g., RNase A and RNase T1) that selectively degrade single-stranded RNAs. Subsequent denaturing polyacrylamide gel electrophoresis provides a means for quantitation and also gives the size of the region hybridized by the probe. Multiple probes can be used to simultaneously track a small number of genes of interest, including a housekeeping gene as a control.

For both Northern blot and RPA, the accuracy and precision of quantitation are functions of the detection method and the reference or standard utilized (as discussed above). Most commonly, the probes are radiolabeled with ${ }^{32} \mathrm{P}$ or ${ }^{33} \mathrm{P}$, in which case the final gel is exposed to X-ray film or phosphor screen and the intensity of each band quantified with a densitometer or phosphor imager, respectively. In both cases, the exposure time can be adjusted to suit the sensitivity required, but the phosphorbased technique is generally more sensitive and has a greater dynamic range. As an alternative to using radioactivity, probes can be labeled with an antigen or hapten, which is subsequently bound by a horseradish peroxidase- or alkaline phosphatase-conjugated antibody and quantified after addition of substrate by chemiluminesence on film or a fluorescence imager (Roda et al., 2000). In all of these imaging applications, subtraction of the background from a neighboring region of gel without probe should be performed. The great advantage of the gel format is that any reference standards can be imaged simultaneously with the sample. Likewise, detection of a housekeeping gene is performed under the same conditions for all samples. As discussed above, the greatest issue in use of a housekeeping gene for relative quantitation is ensuring that its expression is truly conserved for all of the sample types being compared.

Table 1. Characteristics of oligonucleotide vs. cDNA microarrays. Here, "probe" designates the immobilized molecules representing genes of interest and "target" designates molecules of interest in the samples of extracted RNAs.

\begin{tabular}{ccc}
\hline Property & Oligonucleotide arrays & cDNA microarrays \\
\hline Need known sequence? & Yes & No \\
Need physical clone? & No & Yes \\
Probe length (nucleotides) & $30-40$ & $500-1000$ \\
Internal control & Mismatched probes & Background subtraction \\
Maximum elements/array & $10^{6}-10^{5}$ & cDNA \\
Target form & cRNA & Two-color fluorescence \\
Detection & One-color fluorescence
\end{tabular}




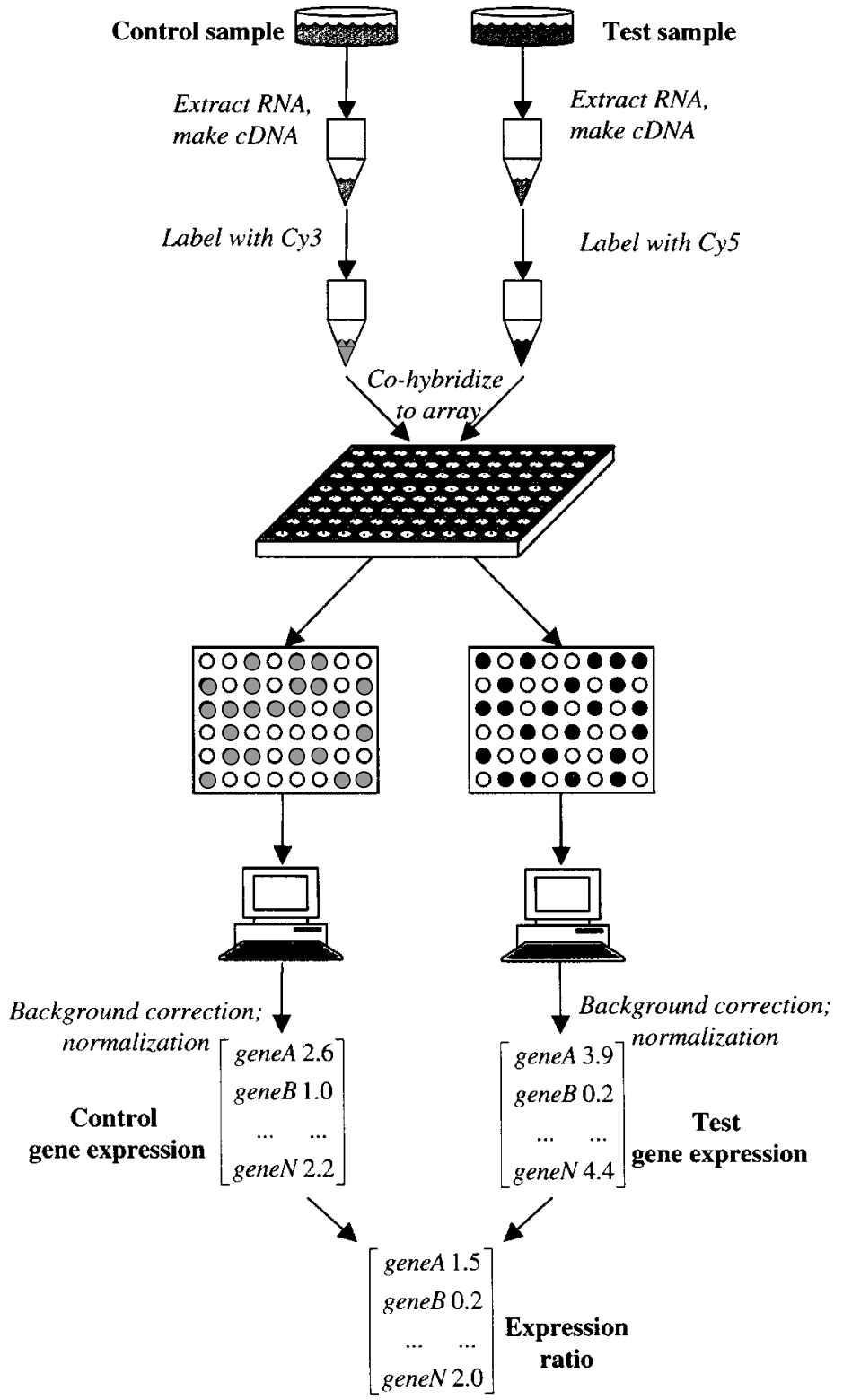

Figure 1. A cDNA microarray experiment. RNA is extracted from control and test samples, reverse transcribed and fluorescently labeled, and co-hybridized to a microarray. After background correction the fluorescence intensities are normalized and reported as ratios of test/control expression for each gene.

\section{DNA Microarrays}

\section{Construction of Microarrays}

Two technologies have emerged for the construction of DNA microarrays (Table 1). Generally, the starting point in each case for the design of an array is a set of sequences corresponding to the genes or putative genes to be probed. In the first approach, oligonucleotide probes are synthesized chemically beginning from a glass substrate. Because of the variable efficiency of oligonucleotide hybridization to CDNA probes, multiple oligonucleotide probes are synthesized complementary to each gene of interest. Furthermore, for each fully complementary oligonucleotide on the array, an oligonucleotide with a mismatch at a single nucleotide position is constructed and used for normalization. Oligonucleotide arrays are routinely created with densities of $10^{4}-10^{5}$ probes $/ \mathrm{cm}^{2}$; the upper limit with currently used photolithographic techniques would be $10^{6}$ probes $/ \mathrm{cm}^{2}$ (Roth and Yarmush, 1999).

The second major technology for DNA microarray construction is the robotic printing of cDNA probes directly onto a glass slide or other suitable substrate. A DNA clone is obtained for each gene of interest, purified, and amplified from a common vector by PCR using universal primers. The probes are generated and checked computationally for non-redundancy; however, within this constraint, longer 
probes are preferred as they improve the kinetics of hybridization and the final signal intensity (Stillman and Tonkinson, 2001). The probes are robotically deposited in spots on the order of $50-200 \mu \mathrm{m}$ in size. At this spacing, a density of approximately $10^{3}$ probes $/ \mathrm{cm}^{2}$ can be achieved (Roth and Yarmush, 1999).

In a cDNA gene expression profiling experiment, a control and a treatment (or disease) sample are hybridized to the same microarray simultaneously (Figure 1). RNA is extracted from each sample and reverse transcribed to obtain cDNA. Either poly(A) RNA (i.e., mRNA) or total RNA may be obtained in the extraction; researchers have been successful with each approach. Typically, one sample is labeled with Cy3 and the other with Cy5, although other dyes (e.g., Alexa) are being developed to improve signal intensity and stability (Wildsmith et al., 2001). After hybridization and washing, the fluorescence is measured by laser scanning confocal microscopy.

In an oligonucleotide array experiment, RNA is extracted and reverse transcribed to produce cDNA, as with a cDNA microarray, except without label incorporation. In this case, the cDNA is transcribed in the presence of a label (e.g., biotin or fluorescein) to produce cRNA. The labeled cRNA is hybridized to an oligonucleotide array, also under conditions of elevated temperature. In this case, normalization is conducted by subtracting from the observed binding (as measured by fluorescence or otherwise) the binding of the cRNA to a mismatched control oligonucleotide. Furthermore, about 25 different oligonucleotides are used for each gene, and the results reported for each gene are an average over the normalized intensities of the 25 different probes.

\section{Quantifying Microarray Data}

Microarray hybridization is clearly a very powerful method to obtain entire gene expression profiles in a single experiment. However, the nature of the technique and the large amount of data produced result in a situation where quantitation is difficult, and the rules governing quantitative analysis of microarray experiments are still unfolding. There are two major, interrelated issues in microarray quantitation. First, it is desirable to have the overall signal/noise ratio be as large as possible, because of the sensitivity needed for detecting low abundance transcripts. Second, careful normalization and statistical analysis are necessary to be able to accurately and quantitatively describe differences in gene expression among genes and/or samples. In this discussion, we focus on cDNA arrays, although many of the same issues apply to oligonucleotide arrays as well. The raw data from microarray experiments are digital images of the fluorescent intensities of each channel (e.g., red and green from Cy5 and Cy 3 respectively) over the entire slide. These are translated into expression ratios of treatment/control for each gene under one or more experimental conditions. The overall quality of these images is a function of the sample preparation technique, fluorescent dye coupling method, probe immobilization, hybridization conditions and detection method.

Once the fluorescence images are obtained, the major challenges of data analysis begin. The raw image represents total fluorescence intensity on a pixel by pixel basis, and this needs to be transformed as accurately as possible to measures of specific binding of targets to each probe. Image processing software programs are widely available to register the image with respect to the original arraying grid and to perform adjustments for slight deviations that occur in the actual printing process. Next, the background is subtracted; this can be done either via a global or local subtraction method. Local background subtraction is generally preferred, as it is felt that the background varies over different regions of a slide (Hess et al., 2001). However, local subtraction leads to a significant number of negative intensity values, indicating that the intensity in the spot is actually slightly lower than in the immediately surrounding area used to determine the local background (Brown et al., 2001). The local background in these areas is typically higher than the overall slide background, so use of the latter can avoid the generation of negative intensities. A related issue is the fact that spot intensities represent an integral over a number of pixels, which individually may have highly varying intensity values. The variance in pixel intensities may prove a useful metric in assessing the significance of measured spot intensities and their corresponding ratios, and in fact for evaluating the quality of an entire slide (Brown et al., 2001).

After image processing and background subtraction, fluorescence intensities are normalized to account for differences in intensities between dyes (e.g., Cy3 vs. Cy5), which can change with time due to storage conditions or photodegradation. Furthermore, the extent of dye incorporation varies according to gene sequence, and slide to slide variability in hybridization exists for a variety of reasons. Several approaches to normalization are available. By analogy with conventional gene expression measurements, the fluorescence of housekeeping genes can be used as a standard. In the microarray format, whole sets of housekeeping genes can be used, which allows better evaluation and accounting of the possibility of differential expression of house keeping genes under experimental conditions of interest. Alternatively, sets of housekeeping genes can be inferred directly from the data using a rank invariant analysis (Tseng et al., 2001). The other major approach to normalization is to add consistent quantities of exogenous mRNA molecules, from a species different than that being studied, to each sample and to also incorporate probes for these standards on the array (Eickhoff et al., 1999). Even after these normalization steps, spot-to-spot variation in hybridization intensity is not necessarily proportional to variation in expression levels, because of differences in dye incorporation and in probe:target binding affinity. Thus, the normalized fluorescence values are always reported as expression ratios of a treatment sample to a control. The absolute values of intensity are important, nonetheless, as they impact on the reliability of the expression ratio. That is, lower intensity values vary more on a percentage basis due to experimental noise; consequently, deviations from unity are less significant when they are ratios of small numbers than of large numbers.

Since expression ratios, even after rigorous image analysis and normalization, will still have variable quality associated with them, replicates are needed for both assessment and improvement of the data quality. 
Depending on the number of genes in the probe set, multiple copies of each probe may be printed in different locations on each slide. The coefficient of variation of ratios over the slide then provides a "quality index" for each slide, and can be used to establish criteria for filtering out data points of unacceptable quality (Tseng et al., 2001). If data are removed due to poor quality or obvious artifacts (e.g., scratches on slides), matrix-based methods for clustering genes or conditions (e.g., hierarchical clustering or principal components analysis) cannot be used; hence, statistical methods for estimating missing data values are under consideration (Troyanskaya et al., 2001). The cost, effort, and lab-to-lab variability of microarray experiments has thus far precluded any consensus on how many replicates are needed for statistical confidence; nonetheless, tests on model samples with known variations in target content suggest that three replicates may be appropriate (Lee et al., 2000). Because the number of replicates is low, standard statistical techniques, such as $t$-tests, may need to be modified to be valid (Baldi and Long, 2001). Ultimately, each researcher will have to find the number of replicates appropriate to the experimental question being asked. For example, the data quality required to identify confidently novel genes would be higher than that required to be used in a data reduction classification of states, such as with principal components analysis.

\section{PCR-Based Methods}

While DNA microarrays and display-based screening methods are powerful tools for identifying genes that are differentially regulated under certain conditions, there is a need for more quantitative techniques, both to verify findings from the former techniques as well as to provide more accurate and precise measurements that will be needed in applications ranging from medical diagnostics to the creation of in silico cellular models. Following reverse transcription of a target mRNA to cDNA, PCR amplification can generate enough material to be measured by staining with DNA-binding dyes. However, the conventional RT$\mathrm{PCR}$ technique is not considered to be quantitative, as the final amount of PCR product is related not just to the initial template concentration but also to primer-dimer accumulation, PCR product re-annealing, and DNA polymerase binding to primers (Brownie et al., 1997; Wittwer et al., 1997a). Furthermore, densitometry of bands obtained by gel electrophoresis typically results in a limited dynamic range of one to two orders of magnitude (Halford et al., 1999; Schmittgen et al., 2000). The most quantitative end-point PCR assays are based on competition between the sample and an in vitro transcribed RNA with the same primer binding site but different length (for distinction in an electrophoretic gel) (Gilliland et al., 1990; Raeymaekers, 1993). With careful controls and standards, these methods can provide accurate quantitation of transcript abundance but still are rather limited in sensitivity and dynamic range.

A promising alternative that has emerged in the last few years is the use of kinetic PCR (kPCR; now often called real-time $\mathrm{PCR}$ ) to provide a more accurate representation of starting template levels. In KPCR, the accumulation of PCR products is monitored at the end of each cycle by fluorescence. During early cycles, the fluorescence is indistinguishable from background, and after many cycles the amount of product reaches a plateau; in between, a region where the fluorescence increases exponentially is observed. The PCR cycle number at which the fluorescence crosses a threshold, which is within the exponential phases, can be related to the amount of starting material; samples with more starting template will achieve the threshold fluorescence level more rapidly than those with less starting template. Instruments that are able to combine rapid thermal cycling with on-line fluorescence detection have emerged to capitalize on this approach (e.g., (Wittwer et al., 1997b)).

Fluorescence detection of PCR product can be achieved in any one of several different approaches. Then simplest approach is to use a dye that binds to doublestranded DNA, such as SYBR Green. While the sensitivity is usually quite good, such dyes bind to any double stranded DNA and thus do not distinguish between the PCR product of interest and alternate products, primerdimers, etc. The product of interest should therefore be validated in assay development by stopping the kinetic PCR reaction after various numbers of cycles and performing electrophoresis on the products in an agarose gel.

A more specific approach is afforded by the use of hybridization probes, consisting of two oligonucleotides that bind to adjacent sites on the PCR product. The 3'-end of one oligonucleotide is labeled with a donor probe (e.g., fluorescein) and the 5'-end of the other oligonucleotide is labeled with an acceptor probe (e.g., rhodamine); thus, specific binding of both probes results in acceptor fluorescence upon excitation of the donor. Another specific technique is the use of the fluorogenic 5'-nuclease assay, in which a specific probe for PCR product is labeled with a reporter dye at the 5'-end and a quencher dye at the 3'end. The Taq DNA polymerase exhibits endonucleolytic activity and cleaves the quencher dye after first binding to and unlinking the amplified DNA (Wilhelm et al., 2001). In both of these cases, probe design is more complicated but potentially rewarded by improved specificity.

In practice, any of the fluorescence probes can be used to achieve excellent performance. In one study, assays using either SYBR Green or TaqMan probes were able to provide 4-5 orders of magnitude in dynamic range with much greater sensitivity than ribonuclease protection assay or end-point RT-PCR with densitometric detection (Schmittgen et al., 2000; Wang and Brown, 1999). The lowest coefficients of variation were achieved using SYBR Green, despite its lower specificity as compared to fluorogenic hybridization probes (Schmittgen et al., 2000).

In quantifying the results of a kPCR assay, an overlooked but potentially important step is the reverse transcription. In this step, a cDNA copy is made of the target $\mathrm{RNA}$; in principle, a resulting cDNA concentration equal to the concentration of RNA target could be obtained. In practice, the resulting quantity of cDNA template, $N_{0}$, is less than the amount of $\mathrm{mRNA}$, i.e.

$$
N_{\mathrm{O}}=M_{\mathrm{O}} \varepsilon_{\mathrm{RT}}
$$

where $\varepsilon_{\mathrm{RT}}$ is the fractional efficiency of the RT step. It has been reported that $\varepsilon_{\mathrm{RT}}$ may vary between $5 \%$ and $90 \%$, because of the high sensitivity of reverse transcriptase 
A)

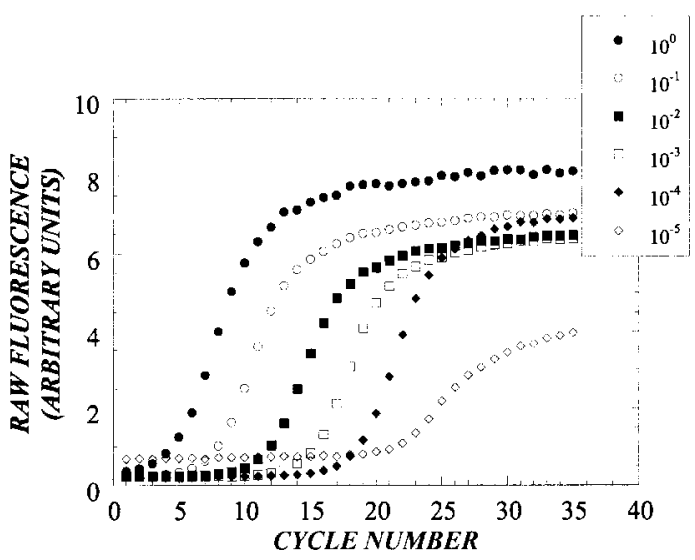

B)

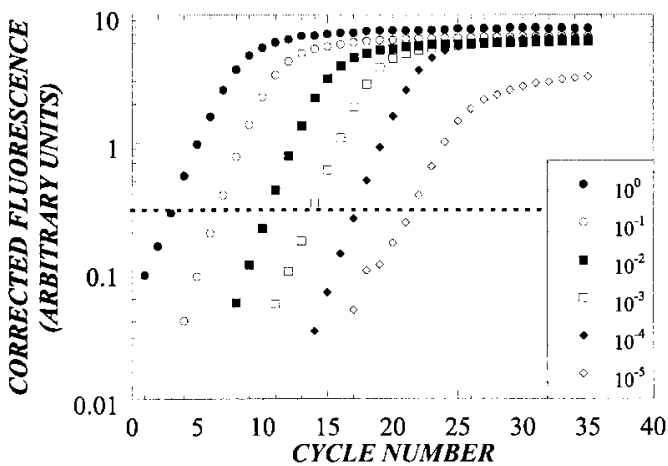

C)

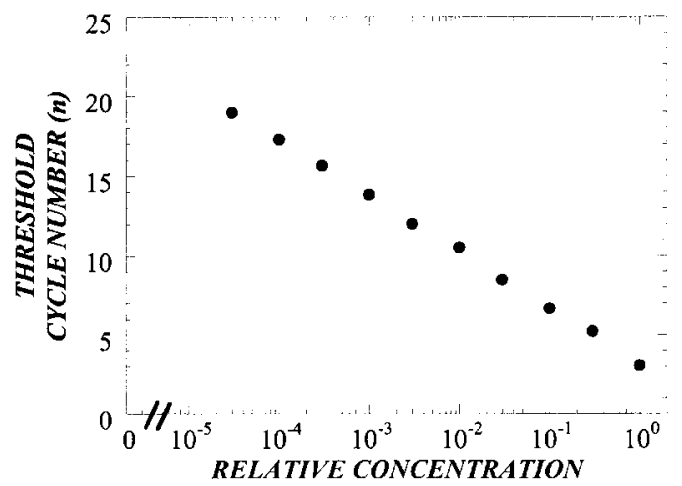

Figure 2. Kinetic PCR dilution series using $18 \mathrm{~S}$ cDNA. A: Raw fluorescence data for dilutions of a stock solution of $18 \mathrm{~S}$ cDNA, ranging in relative concentration from 1 to $1 \times 10^{-5}$. B: Background corrected fluorescence showing parallel curves passing a threshold (arbitrarily set within the regime of exponential growth of fluorescence with respect to cycle number) at equally spaced intervals of roughly 3.3 cycles/10-fold change in concentration. C: Standard curve of threshold cycle number $(n)$ vs. $\log (c)$. Dotted line represents a best logarithmic fit $\left(n=3.21-3.51 \log (c) ; r^{2}=0.999\right)$ to the data.

enzymes to salts and organics that may be residual from mRNA extraction protocols (Freeman et al., 1999); however, with consistent protocols the variation can be made significantly less. Errors on the order of $10 \%$ will be well tolerated, as this level of precision is less than that for the PCR phase of the assay.

During the exponential phase of PCR, the amount of product grows exponentially at each cycle, until a plateau regime is reached (Figure 2a). Before the plateau region, the number of copies of PCR product, $N$, grows exponentially from its initial value, $N_{0}$, over the course of $n$ cycles according to:

$$
N=N_{0}(1+\varepsilon)^{n}
$$

where $\varepsilon$ is the efficiency of the PCR reaction, which is usually between 0.8 and 1.0 and often assumed to be identically unity. The measured fluorescence should be directly proportional to the amount of product, but only after background fluorescence is subtracted (Figure $2 b$ ). Thus (again, before the plateau region is reached), the corrected fluorescence is related to the amount of starting template and the number of cycles by:

$$
F=\alpha N_{0}(1+\varepsilon)^{n}
$$

where $\alpha$ is a proportionality constant. In analyzing a series of samples, standards and/or unknowns, a threshold fluorescence level is chosen such that all of the samples are in the exponential phase when their fluorescence crosses the threshold (Figure 2b). The cycle number, $n$, at which the fluorescence crosses the threshold is recorded for each sample, and the mRNA level of the sample can then be quantified in one of two ways.

It is common in real-time PCR, as in other mRNA quantification methods, to employ a housekeeping gene, the choice of which requires judicious consideration, as discussed earlier. The number of copies of transcript from the gene of interest, $N_{\mathrm{g}}$, is then always expressed relative to the number of copies of the housekeeping gene, $N_{\text {hk }}$. Even so, a normalization between treatment and control samples is necessary for quantitation, as the variable efficiency of the PCR reaction leads to an error that is amplified at each cycle. The ratio $N_{\mathrm{g}} / N_{\mathrm{hk}}$ calculated from Eq. (3) is quite sensitive to the exact value of the efficiency (Table 2, Column 2). Assuming that the efficiencies are equal to unity can lead to large errors in the values for expression of the gene of interest relative to the housekeeping gene (Table 2, Column 3). However, if the efficiency of each gene (target and housekeeping) is constant between the treatment and control samples (i.e., determined principally by the primer-template hybridization rather than by sample variation), then the error is largely compensated and only linear in the difference of efficiencies between the housekeeping gene and the gene of interest (Table 2, Column 4). The most rigorous method would be to use the individual efficiency for each sample, which can be directly calculated from the slope of log (Fluorescence) vs. cycle number plots such as Figure $2 b$, in which case the expression ratio is calculated from:

$$
\frac{\left(N_{\mathrm{g}} / \mathrm{N}_{h k}\right)_{\text {treatment }}}{\left(N_{\mathrm{g}} / \mathrm{N}_{\text {hk }}\right)_{\text {control }}}=\frac{\left(1+\varepsilon_{h k}\right) n^{n_{h k t}} /\left(1+\varepsilon_{g t}\right)^{n_{g t}}}{\left(1+\varepsilon_{h k c}\right)^{n_{h k c}} /\left(1+\varepsilon_{g c}\right)^{n_{g c}}}
$$


Table 2. Effects of PCR efficiency on expression calculations ${ }^{*}$

\begin{tabular}{|c|c|c|c|}
\hline$\varepsilon_{g}$ & $\left(N_{\mathrm{g}} / N_{\mathrm{hk}}\right)_{\text {actual }}$ & $\left(N_{\mathrm{g}} / N_{\mathrm{hk}}\right)_{\text {actual }} /\left(N_{\mathrm{g}} / N_{\mathrm{hk}}\right)_{\text {apparent }}$ & $\left(N_{\mathrm{g}} / N_{\text {hk }}\right)_{\text {treatment }} /\left(N_{\mathrm{g}} / N_{\mathrm{hk}}\right)_{\text {control }}$ \\
\hline 0.95 & 0.035 & 1.135 & 1.95 \\
\hline 0.90 & 0.060 & 1.908 & 1.90 \\
\hline 0.85 & 0.102 & 3.253 & 1.85 \\
\hline 0.80 & 0.176 & 5.626 & 1.80 \\
\hline 0.75 & 0.309 & 9.883 & 1.75 \\
\hline 0.70 & 0.551 & 17.648 & 1.70 \\
\hline
\end{tabular}

*Example simulated based on actual values $\varepsilon_{\mathrm{hk}}=0.95, n_{\mathrm{hk}}=15, n_{\mathrm{g}}=20 .\left(N_{\mathrm{g}} / N_{\mathrm{hk}}\right)_{\text {apparent }}$ is the value obtained using Eq. (3) and assuming $100 \%$ efficiency, i.e., $\varepsilon_{\mathrm{hk}}=\varepsilon_{\mathrm{g}}=1.0$. For the last column, threshold cycle numbers of $\left(n_{\mathrm{g}}\right)_{\text {treatment }}=18$ and $\left(n_{\mathrm{g}}\right)_{\text {control }}=20$ are simulated.

where the subscripts $t$ and $c$ are appended to indicate treatment and control samples, respectively.

Alternatively, a series of mRNA or cDNA dilutions can be used to construct a standard curve (Figure 2c). Setting the threshold fluorescence constant for a sample of starting concentration $N$ vs. a standard of concentration $N_{0}$ gives the form of the standard curve plot (Jayaraman et al., 2001):

$$
n-n_{\text {ref }}=-\frac{1}{\log (1+\varepsilon)} \log \left(N / N_{\text {ref }}\right)
$$

Here, a constant or average value of $\varepsilon$ is assumed, which can be extracted from the slope of the plot (Figure 2c); the linearity of the plot suggests that the condition is likely well enough satisfied.

\section{Summary}

Quantitative measurements of gene expression are important for a wide range of research and diagnostic applications. A number of approaches to measuring gene expression are available, all of which center around the use of a sequence-specific probe to identify the target of interest. While the technical considerations in each approach differ markedly, the most important features in quantitation are common among them: specificity of the probe and the proper use of housekeeping genes and/or exogenous standards as controls. An important consideration in the use of housekeeping genes is to ensure that they are expressed at constant levels under the conditions of interest; therefore, ribosomal RNAs may be superior to mRNA species, and the use of multiple housekeeping genes where possible is preferred. The use of standards is possibly the most quantitatively accurate approach, though doing so adds to the number of samples that must be processed and, in that regard, can actually add to experimental error. With these concepts and modern equipment developments, gene expression levels can now be monitored with high accuracy and an increasing level of throughput.

\section{Acknowledgements}

The author thanks Arul Jayaraman for helpful discussions and for the data in Figure 2. The author's work in this area was supported by the Whitaker Foundation.

\section{References}

Baldi, P., and Long, A.D. 2001. A Bayesian framework for the analysis of microarray expression data: regularized t-test and statistical inferences of gene changes. Bioinformatics. 17: 509-519.

Brown, C.S., Goodwin, P.C., and Sorger, P.K. 2001. Image metrics in the statistical analysis of DNA microarray data. Proc. Natl. Acad. Sci. USA. 98: 8944-8949.

Brownie, J., Shawcross, S., Theaker, J., Whitcombe, D., Ferrie, R., Newton, C., and Little, S. 1997. The elimination of primer-dimer accumulation in PCR. Nucl. Acids Res. 25: 3235-3241.

Cao, S.X., Dhahbi, J.M., Mote, P.L., and Spindler, S.R. 2001. Genomic profiling of short- and long-term caloric restriction effects in the liver of aging mice. Proc. Natl. Acad. Sci. USA. 98: 10630-10635.

Eickhoff, B., Korn, B., Schick, M., Poustka, A., and van der Bosch, J. 1999. Normalization of array hybridization experiments in differential gene expression analysis. Nucl. Acids Res. 27: e33.

Freeman, W.M., Walker, S.J., and Vrana, K.E. 1999. Quantitative RT-PCR: pitfalls and potential. Biotechniques. 26: 112-22, 124-5.

Gilliland, G., Perrin, S., Blanchard, K., and Bunn, H.F. 1990. Analysis of cytokine mRNA and DNA: detection and quantitation by competitive polymerase chain reaction. Proc. Natl. Acad. Sci. USA. 87: 2725-2729.

Goidin, D., Mamessier, A., Staquet, M.J., Schmitt, D., and Berthier-Vergnes, O. 2001. Ribosomal 18S RNA prevails over glyceraldehyde-3-phosphate dehydrogenase and beta-actin genes as internal standard for quantitative comparison of mRNA levels in invasive and noninvasive human melanoma cell subpopulations. Anal. Biochem. 295: 17-21.

Golub, T.R., Slonim, D.K., Tamayo, P., Huard, C., Gaasenbeek, M., Mesirov, J.P., Coller, H., Loh, M.L., Downing, J.R., Caligiuri, M.A. 1999. Molecular classification of cancer: class discovery and class prediction by gene expression monitoring. Science. 286: 531-537.

Halford, W.P., Falco, V.C., Gebhardt, B.M., and Carr, D.J. 1999. The inherent quantitative capacity of the reverse transcription-polymerase chain reaction. Anal. Biochem. 266: 181-191.

Hess, K.R., Zhang, W., Baggerly, K.A., Stivers, D.N., and 
Coombes, K.R. 2001. Microarrays: handling the deluge of data and extracting reliable information. Trends Biotechnol. 19: 463-468.

Hoffmann, K.F., McCarty, T.C., Segal, D.H., Chiaramonte, M., Hesse, M., Davis, E.M., Cheever, A.W., Meltzer, P.S., Morse, H.C., 3rd, and Wynn, T.A. 2001. Disease fingerprinting with cDNA microarrays reveals distinct gene expression profiles in lethal type 1 and type 2 cytokinemediated inflammatory reactions. FASEB. J. 15: 25452547.

Jayaraman, A., Walton, S.P., Yarmush, M.L., and Roth, C.M. 2001. Rational selection and quantitative evaluation of antisense oligonucleotides. Biochim. Biophys. Acta. 1520: 105-114.

Jayaraman, A., Yarmush, M.L., and Roth, C.M. 2000. Dynamics of gene expression in rat hepatocytes under stress. Metabolic Eng. 2: 239-251.

Kang, J.J., Kaysen, G.A., Jones Jr., H., and J., H.M. 1997. Rat liver transcript profiling in normal and disease states using a kinetic polymerase chain reaction assay. Methods: A Companion to Meth. Enzymol. 13: 437-443.

Khan, J., Wei, J.S., Ringner, M., Saal, L.H., Ladanyi, M., Westermann, F., Berthold, F., Schwab, M., Antonescu, C.R., Peterson, C. and others. 2001. Classification and diagnostic prediction of cancers using gene expression profiling and artificial neural networks. Nat. Med. 7: 673679.

Lee, M.L., Kuo, F.C., Whitmore, G.A., and Sklar, J. 2000. Importance of replication in microarray gene expression studies: statistical methods and evidence from repetitive cDNA hybridizations. Proc. Natl. Acad. Sci. USA. 97: 9834-9839.

Livesey, F.J., Furukawa, T., Steffen, M.A., Church, G.M., and Cepko, C.L. 2000. Microarray analysis of the transcriptional network controlled by the photoreceptor homeobox gene Crx. Curr. Biol. 10: 301-310.

Raeymaekers, L. 1993. Quantitative PCR: theoretical considerations with practical implications. Anal. Biochem. 214: 582-585.

Roda, A., Pasini, P., Guardigli, M., Baraldini, M., Musiani, M., and Mirasoli, M. 2000. Bio- and chemiluminescence in bioanalysis. Fresenius J. Anal. Chem. 366: 752-759.

Roth, C.M., and Yarmush, M.L. 1999. Nucleic acid biotechnology. Ann. Rev. Biomed. Eng. 1: 265-297.

Schmittgen, T.D., and Zakrajsek, B.A. 2000. Effect of experimental treatment on housekeeping gene expression: validation by real-time, quantitative RT-PCR.
J. Biochem. Biophys. Methods. 46: 69-81.

Schmittgen, T.D., Zakrajsek, B.A., Mills, A.G., Gorn, V., Singer, M.J., and Reed, M.W. 2000. Quantitative reverse transcription-polymerase chain reaction to study mRNA decay: comparison of endpoint and real-time methods. Anal. Biochem. 285: 194-204.

Stillman, B.A., and Tonkinson, J.L. 2001. Expression microarray hybridization kinetics depend on length of the immobilized DNA but are independent of immobilization substrate. Anal. Biochem. 295: 149-157.

Troyanskaya, O., Cantor, M., Sherlock, G., Brown, P., Hastie, T., Tibshirani, R., Botstein, D., and Altman, R.B. 2001. Missing value estimation methods for DNA microarrays. Bioinformatics. 17: 520-525.

Tseng, G.C., Oh, M.K., Rohlin, L., Liao, J.C., and Wong, W.H. 2001. Issues in cDNA microarray analysis: quality filtering, channel normalization, models of variations and assessment of gene effects. Nucl. Acids Res. 29: 25495257.

Wang, T., and Brown, M.J. 1999. mRNA quantification by real time TaqMan polymerase chain reaction: validation and comparison with RNase protection. Anal. Biochem. 269: 198-201.

Warrington, J.A., Nair, A., Mahadevappa, M., and Tsyganskaya, M. 2000. Comparison of human adult and fetal expression and identification of 535 housekeeping/ maintenance genes. Physiol. Genomics. 2: 143-147.

Weindruch, R., Kayo, T., Lee, C.K., and Prolla, T.A. 2001. Microarray profiling of gene expression in aging and its alteration by caloric restriction in mice. J. Nutr. 131: 918S923S.

Wildsmith, S.E., Archer, G.E., Winkley, A.J., Lane, P.W., and Bugelski, P.J. 2001. Maximization of signal derived from cDNA microarrays. Biotechniques. 30: 202-6, 208. Wilhelm, J., Pingoud, A., and Hahn, M. 2001. Comparison between Taq DNA polymerase and its Stoffel fragment for quantitative real-time PCR with hybridization probes. Biotechniques. 30: 1052-1060.

Wittwer, C.T., Herrmann, M.G., Moss, A.A., and Rasmussen, R.P. 1997a. Continuous fluorescence monitoring of rapid cycle DNA amplification. Biotechniques. 22: 130-1, 134-138.

Wittwer, C.T., Ririe, K.M., Andrew, R.V., David, D.A., Gundry, R.A., and Balis, U.J. 1997b. The LightCycler: a microvolume multisample fluorimeter with rapid temperature control. Biotechniques. 22: 176-181. 


\section{Further Reading}

Caister Academic Press is a leading academic publisher of advanced texts in microbiology, molecular biology and medical research. Full details of all our publications at caister.com

- MALDI-TOF Mass Spectrometry in Microbiology Edited by: M Kostrzewa, S Schubert (2016) www.caister.com/malditof

- Aspergillus and Penicillium in the Post-genomic Era Edited by: RP Vries, IB Gelber, MR Andersen (2016) www.caister.com/aspergillus2

- The Bacteriocins: Current Knowledge and Future Prospects Edited by: RL Dorit, SM Roy, MA Riley (2016)

www.caister.com/bacteriocins

- Omics in Plant Disease Resistance Edited by: V Bhadauria (2016) www.caister.com/opd

- Acidophiles: Life in Extremely Acidic Environments Edited by: R Quatrini, DB Johnson (2016) www.caister.com/acidophiles

- Climate Change and Microbial Ecology: Current Research and Future Trend

Edited by: J Marxsen (2016)

www.caister.com/climate

- Biofilms in Bioremediation: Current Research and Emerging Technologies

Edited by: G Lear (2016)

www.caister.com/biorem

- Microalgae: Current Research and Applications Edited by: MN Tsaloglou (2016) www.caister.com/microalgae

- Gas Plasma Sterilization in Microbiology: Theory, Applications, Pitfalls and New Perspectives Edited by: H Shintani, A Sakudo (2016) www.caister.com/gasplasma

- Virus Evolution: Current Research and Future Directions Edited by: SC Weaver, M Denison, M Roossinck, et al. (2016) www.caister.com/virusevol

- Arboviruses: Molecular Biology, Evolution and Control Edited by: N Vasilakis, DJ Gubler (2016) www.caister.com/arbo

- Shigella: Molecular and Cellular Biology Edited by: WD Picking, WL Picking (2016) www.caister.com/shigella

-Aquatic Biofilms: Ecology, Water Quality and Wastewater Treatment

Edited by: AM Romaní, H Guasch, MD Balaguer (2016)

www.caister.com/aquaticbiofilms

- Alphaviruses: Current Biology

Edited by: S Mahalingam, L Herrero, B Herring (2016)

www.caister.com/alpha

- Thermophilic Microorganisms

Edited by: F Li (2015)

www.caister.com/thermophile
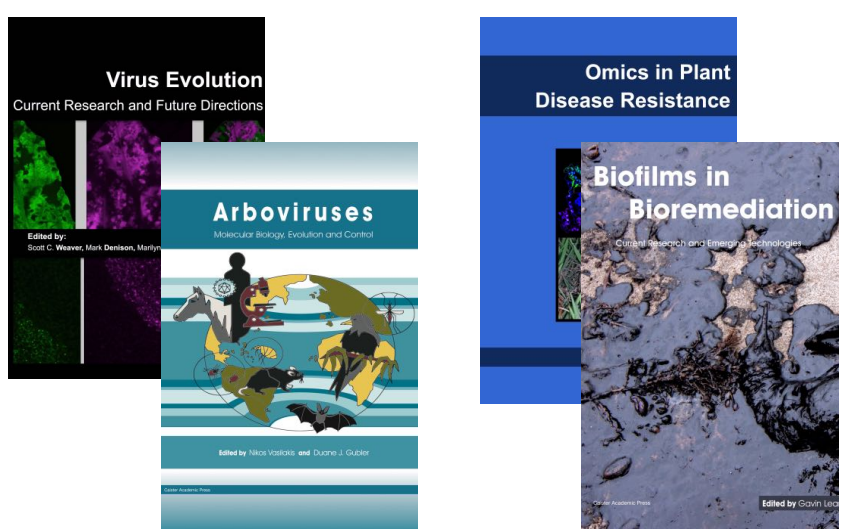
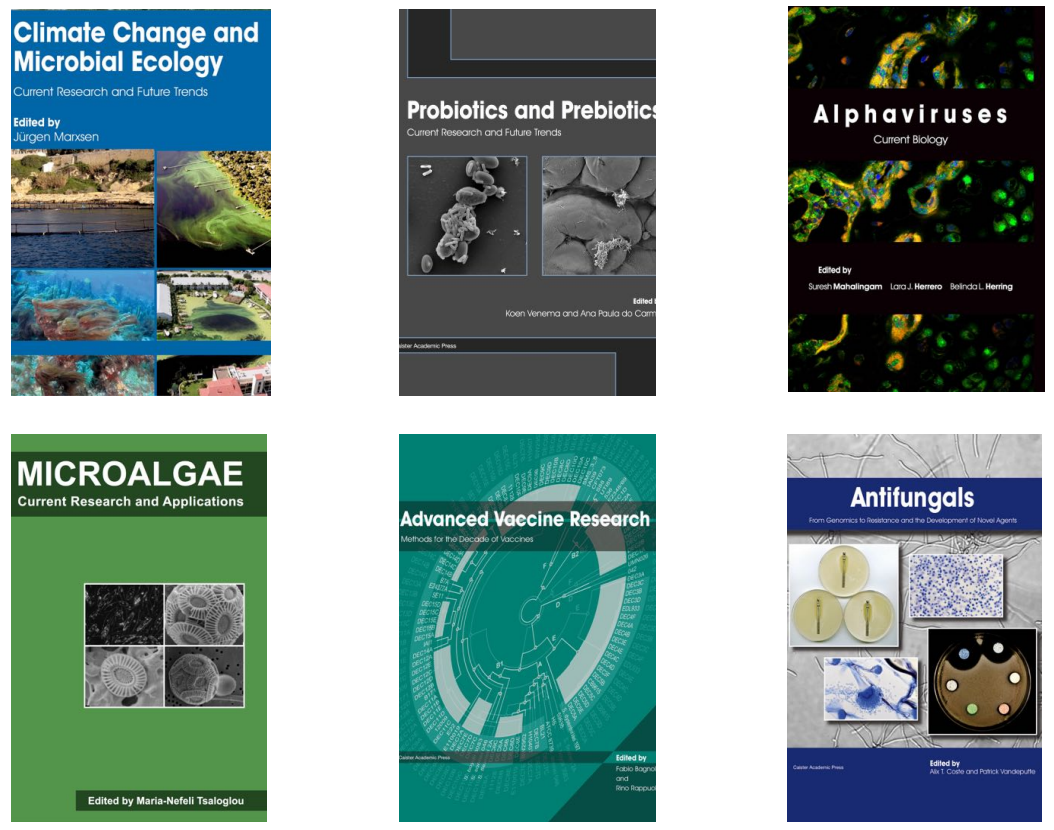

- Flow Cytometry in Microbiology: Technology and Applications Edited by: MG Wilkinson (2015) www.caister.com/flow

- Probiotics and Prebiotics: Current Research and Future Trends Edited by: K Venema, AP Carmo (2015) www.caister.com/probiotics

- Epigenetics: Current Research and Emerging Trends Edited by: BP Chadwick (2015) www.caister.com/epigenetics2015

- Corynebacterium glutamicum: From Systems Biology to Biotechnological Applications

Edited by: A Burkovski (2015)

www.caister.com/cory2

- Advanced Vaccine Research Methods for the Decade of Vaccines

Edited by: F Bagnoli, R Rappuoli (2015)

www.caister.com/vaccines

- Antifungals: From Genomics to Resistance and the Development of Novel Agents

Edited by: AT Coste, P Vandeputte (2015)

www.caister.com/antifungals

- Bacteria-Plant Interactions: Advanced Research and Future Trends Edited by: J Murillo, BA Vinatzer, RW Jackson, et al. (2015) www.caister.com/bacteria-plant

\section{- Aeromonas}

Edited by: J Graf (2015)

www.caister.com/aeromonas

- Antibiotics: Current Innovations and Future Trends

Edited by: S Sánchez, AL Demain (2015)

www.caister.com/antibiotics

- Leishmania: Current Biology and Contro Edited by: S Adak, R Datta (2015) www.caister.com/leish2

- Acanthamoeba: Biology and Pathogenesis (2nd edition) Author: NA Khan (2015)

www.caister.com/acanthamoeba2

- Microarrays: Current Technology, Innovations and Applications Edited by: Z He (2014)

www.caister.com/microarrays2

- Metagenomics of the Microbial Nitrogen Cycle: Theory, Methods and Applications

Edited by: D Marco (2014)

www.caister.com/n2 